\title{
Binding of Cationic Mixed Micelles to Pyrene-Labeled Poly((acrylamido)-2-methylpropanesulfonate)
}

\section{K. Yoshida,t,\$ Y. Morishima, ${ }^{\ddagger}$ P. L. Dubin, ${ }^{*, t}$ and M. Mizusaki ${ }^{\ddagger}$}

Department of Chemistry, Indiana-Purdue University, Indianapolis, Indiana 46202, and Department of Macromolecular Science, Osaka University, Toyonaka, Osaka, $560 \mathrm{~J}$ apan

Received April 25, 1997; Revised Manuscript Received J uly 25, $1997^{\circledR}$

\begin{abstract}
The interaction between pyrene-labeled poly(acrylamido)-2-methylpropane sulfonate) (PyPAMPS) and mixed micelles of n-dodecylhexaoxyethylene glycol monoether/n-hexadecyltrimethylammonium chloride $\left(\mathrm{C}_{12} \mathrm{E}_{6} / \mathrm{CTAC}\right)$ was studied by turbidimetry, quasielastic light scattering (QELS), fluorescence quenching, and UV spectroscopy. The present report focuses on the effect of the pyrene label on the polymer-micelle interaction. With nonlabeled PAMPS, we observe by turbidity and QELS a critical mole fraction of ionic surfactant $\left(Y_{c}\right)$ corresponding to the onset of polyelectrolyte-micelle interaction. The same $Y_{c}$ is observed by turbidity and QELS for PyPAMPS. However, PyPAMPS shows a lower additional transition by the same methods, which we refer to as " $Y_{\mathrm{cl}}$ " to distinguish it from " $Y_{\mathrm{c} 2}$ " which is seen for both PAMPS and PyPAMPS. Steady-state fluorescence, in the presence of a hydrophobic quencher $\left(\mathrm{N}, \mathrm{N}\right.$-dimethylaniline) solubilized in the micelles, also shows a discontinuity at $\mathrm{Y}_{\mathrm{c} 1}$. Therefore, we conclude that $Y_{\mathrm{c} 1}$ and $Y_{\mathrm{c} 2}$ correspond to the binding of micelles to polymeric pyrene sites and AMPS sites, respectively. Analysis of UV spectra at varying $Y$ demonstrates that the polymer-bound pyrene penetrates inside micelles and resides at or near the hydrophobic core. These results indicate preferential binding of micelles to pyrene binding sites; nevertheless, both $Y_{c 1}$ and $Y_{c 2}$ show a linear dependence on the square root of the ionic strength. This dependence suggests the dominant rol e of electrostatic forces, consistent with the observation that nonionic micelles will not bind to PyPAMPS. We conclude that conjoint hydrophobic and electrostatic effects determine the interaction between PyPAMPS and $\mathrm{C}_{12} \mathrm{E}_{6} /$ CTAC mixed micelles.
\end{abstract}

\section{Introduction}

Most of the experimental papers on polymer-surfactant interactions in the past 2 decades (for reviews, see refs $1-4$ ) have dealt either with (a) interactions between polyelectrolytes and oppositely charged surfactants bel ow a critical micellar concentration (CMC) or with (b) association between nonionic polymers and ionic surfactants above the CMC. The former case (a) has typically been discussed in terms of the binding of monomeric surfactants to polyelectrolytes or with the appearance of a polymer-surfactant complex at a critical aggregation concentration of the surfactant (CAC). Electrostatic forces dominate this interaction, although hydrophobic forces may play a secondary role. $^{5-7}$ The latter case (b) is probably best exemplified by the system involving poly (ethylene oxide) (PEO) and sodium dodecyl sulfate (SDS) above the CMC; here, the debate about the nature of the attractive force has included the reduction of interfacial energy between the hydrocarbon core and the local sol vent medium, ${ }^{8-10}$ the association between the ethylene group of PEO and the aliphatic part of micelles, ${ }^{11}$ and the role of the cationic counterion in the stabilization of the complex. ${ }^{12}$ These arguments indicate the difficulty in reaching definitive conclusions on this system.

The lack of investigation for polyelectrolytes with oppositely charged surfactants well above the CMC could at one time be attributed to the presence of interactions so strong that irreversible phase separation occurs. Dubin and co-workers, ${ }^{13-17}$ however, found that these interactions could be attenuated by using mixed micelles of nonionic and ionic surfactants. A number

† Indiana-Purdue University.

‡ Osaka University.

$\S$ Current address: Shiseido Basic Research Lab, Yokohama, $223 \mathrm{~J}$ apan.

${ }^{\otimes}$ Abstract published in AdvanceACS Abstracts, September 15, 1997.

S0024-9297(97)00576-7 CCC: $\$ 14.00$ of studies on polyelectrolytes and oppositely charged mixed micelles ${ }^{13-22}$ have indicated that complex formation appears to be a critical phenomenon in which the primary variables are the ionic strength $(I)$, polymer linear charge density $(\xi)$ and micelle surface charge density $(\sigma)$. The last parameter may be adjusted experimentally in ionic/nonionic mixed micelles via the mole fraction of ionic surfactant, i.e., Y. Many studies demonstrate that $Y_{c}$, a critical value corresponding to the onset of complex formation, varies linearly with square root of the ionic strength $\left(I^{1 / 2}\right)$. Since the Debye length $\left(\kappa^{-1}\right)$ varies as $\mathrm{I}^{-1 / 2}$, this dependence suggests that the interaction is predominantly controlled by an electrostatic force.

Inasmuch as electrostatic forces rule the interaction between polyelectrolytes and oppositely charged mixed micelles, such systems may represent a model for the Coulombic interaction of linear macroions and colloids, for example, the nonspecific binding of DNA to proteins, the formation of complexes between synthetic polyel ectrolytes and proteins, and the flocculation of inorganic colloids by polyions. In this regard, polyelectrolytemicelle systems, in which the colloid surface charge density can be readily altered, are valuable as a model system to test theories for pol yion-colloid interactions. Several ${ }^{23-26}$ theoretical approaches have been devel oped for the adsorption of polyelectrolytes to charged surfaces or micelles and yield results consistent with experimental observations: (a) the interaction energy increases with $\sigma(\propto Y), \xi$, and $\kappa^{-1}\left(\left.\propto\right|^{-1 / 2}\right)$; and (b) the interaction resembles a phase transition.

Many experimental approaches have been used to study polymer-surfactant interactions, such as turbidimetry, ${ }^{13,15}$ light scattering, ${ }^{18-22}$ small-angle neutron scattering, ${ }^{27}$ el ectrophoretic light scattering, ${ }^{28-29} \mathrm{NMR}^{30}$ dialysis, 18,31,32 surface tension, $33-36$ viscometry, 20,33 calorimetry, ${ }^{37}$ dye solubilization ${ }^{38,39}$ and solvatochromic studies ${ }^{40}$, but relatively few techniques can be utilized 
to identify the phase transition. Static ${ }^{20,22,41}$ and quasielastic ${ }^{17,19-21,41}$ light scattering especially have provided important insight into complex structure; nevertheless, they can detect the onset of complex formation only within certain limitations. Methods that depend on light scattered from the complex require a considerable change in particle size and/or mass relative to free polymers and free micelles, and in any event the scattering intensity increases only slightly when either polymer molecular weight 19,20 or concentration 22 is low. As a result, it is hard to define the point of incipient interaction, i.e., $Y_{c}$.

Fluorescence methods have been increasingly employed to examine polymer-surfactant interactions partly because of their inherent sensitivity, although they have not so far been used to study the phase transition of polyelectrolyte-micelle systems. In general, fluorophores have been used in two ways for the study of polymer-surfactant systems. In the first case, monomeric fluorophores such as pyrene are used as fluorescence probes. F or example, pyrene has been used to measure the CAC for poly(styrene sulfonate) (PSS)/ dodecyltrimethylammonium bromide (DTAB), through quenching, ${ }^{42}$ vibrational fine structure shifts $\left(I_{3} / I_{1}\right)^{43}$ and time-dependent fluorescence. 42,43 In the second case, the fluorophore is covalently bound to the polymer chain. Winnik and co-workers studied the interaction between pyrene-labeled neutral polymers (hydroxypropylcellulose, PyHPC; ${ }^{44}$ polyethylene oxide, PyPEO ${ }^{45}$ ) and ionic surfactant (sodium dodecyl sulfate, SDS). Both excimer/ monomer emission ratio $\left(I_{E} / I_{M}\right)$ and $I_{3} / I_{1}$ indicate that these polymers associate with surfactants and form polymer-surfactant complexes below the CMC.

In this work, we propose to use a fluorescence-label ed polymer for characterization of the polyelectrolytemicelle phase transition. We recently reported ${ }^{46}$ on the use of time-resolved fluorescence quenching methods to study dynamic processes of complex formation between a pyrene-labeled polyanion (PyPAMPS) and cationic mixed micelles ( $\left.\mathrm{C}_{12} \mathrm{E}_{6} / \mathrm{CTAC}\right)$. However, in making use of fluorescence-labeled polyelectrolytes, it is important to consider perturbation by the label. In fact, the labeled neutral polymer PyPEO ${ }^{45}$ behaves as a hydrophobically modified polymer even if the mole fraction of pyrene is small ( $\cong 1 \mathrm{~mol} \%$ ), and the pyrene label enhances the hydrophobic association with micelles. Other studies ${ }^{47-50}$ have also shown that hydrophobic modifications strengthen the polymer-surfactant interaction by providing hydrophobic sites to which surfactants bind preferentially. In this report, we discuss the influence of fluorophore in label ed polyel ectrolytes on polyelectrolyte-micelle interactions. For the interaction of PyPAMPS with mixed micelles of $\mathrm{C}_{12} \mathrm{E}_{6} / \mathrm{CTAC}$, turbidimetric, light-scattering, and fluorescence studies reveal that while the binding is predominantly driven by electrostatic forces, micelles do bind preferentially to pyrene sites. We observe a conjoint effect of hydrophobic and electrostatic forces on the polyion-micelle interaction.

\section{Experimental Section}

Materials. PyPAMPS and PAMPS were prepared by polymerization of 2-(acrylamido)-2-methyl propanesulfonic acid with or without $\mathrm{N}$-(1-pyrenylmethyl)-methacrylamide as re ported previously. ${ }^{51}$ The pyrene content of the copolymer $(0.5$ mol \%) was determined by UV absorbance at $343 \mathrm{~nm}$. MW values of PAMPS $\left(1.0 \times 10^{6}\right)$ and PyPAMPS $\left(1.1 \times 10^{5}\right)$ were measured by size exclusion chromatography (SEC) on Super-

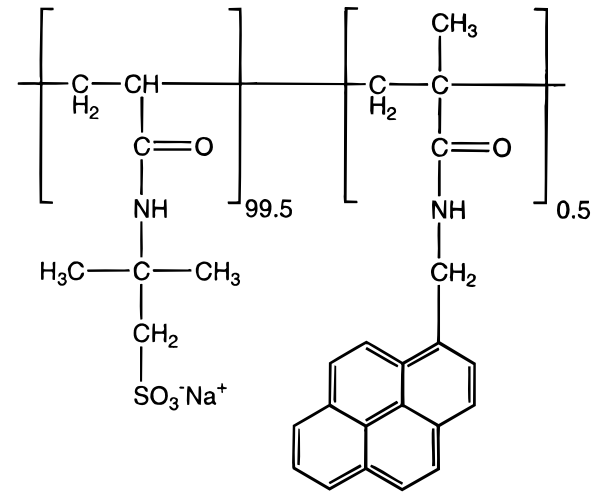

PyPAMPS

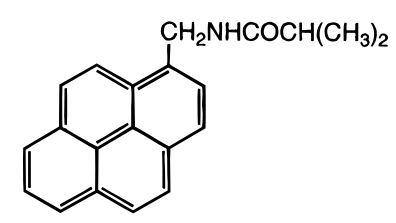

PyPAm

ose 6 columns, relative to pullulan standards. N-(1-pyrenylmethyl)-2-methylpropionamide (PyPAm) was synthesized by the reduction of $\mathrm{N}$-(1-pyrenylmethyl)methacrylamide as described previously. ${ }^{52}$

$\mathrm{C}_{12} \mathrm{E}_{6}$ (Nikko Chemicals) was used without further purification. CTAC (Wako Pure Chemicals) was recrystallized twice from methanol. N,N-Dimethylaniline (DMA) (Aldrich) and $\mathrm{NaCl}$ (Sigma) were used without further purification. Milli-Q water was used through this work.

Turbidimetric Titrations. Turbidimetric titrations were carried out at $420 \mathrm{~nm}$ using a Brinkman PC800 probe colorimeter equipped with a 1-cm path length fiber optics probe; all solutions were filtered through a $0.45 \mu \mathrm{m}$ Whatman filter before titrations. "Type I" turbidimetric titrations $\mathrm{s}^{53,54}$ were performed at $22 \pm 2{ }^{\circ} \mathrm{C}$ by adding a solution of $40 \mathrm{mM}$ CTAC to a mixture of $0.5 \mathrm{~g} / \mathrm{L}$ polymer and $20 \mathrm{mM} \mathrm{C}_{12} \mathrm{E}_{6}$ at constant ionic strengths ( $\mathrm{I}$ ); the ionic strengths were adjusted with $\mathrm{NaCl}$. All transmittance values were corrected by subtracting the turbidity of a polymer-free blank. The blankcorrected turbidity (100 - T\%) was plotted vs $Y$, the mole fraction of ionic surfactant, defined as [CTAC]/([CTAC] + $\left.\left[\mathrm{C}_{12} \mathrm{E}_{6}\right]\right)$. "Type II" titrations, ${ }^{55,56}$ corresponding to addition of the mixed micelle to polymer at constant $Y$ and I, were conducted by adding a mixed solution of $\mathrm{C}_{12} \mathrm{E}_{6} / \mathrm{CTAC}$ to a 0.1 $\mathrm{g} / \mathrm{L}$ polymer solution at $0.3 \mathrm{M} \mathrm{NaCl}$.

Quasielastic Light Scattering. QELS was carried out at $90^{\circ}$ scattering angle with a DynaPro 801 (Protein solutions Inc., Charlottesville, VA), which empl oys a 30-mW solid-state $780 \mathrm{~nm}$ laser and an avalanche photodiode detector. The sample solution was introduced into the 7- $\mu \mathrm{L}$ cell via $0.2 \mu \mathrm{m}$ Whatman Anotop filters. Scattering data were analyzed by monomodal analysis using the Nelder-Meade Simplex al gorithm. The hydrodynamic radius $\left(R_{h}\right)$ was calculated from the measured translational diffusion coefficient using the StokesEinstein equation.

Fluorescence Titrations. Steady-state fluorescence spectra were recorded on a FLU ORO IV fluorescence spectrophotometer (Gilford, Oberlin, $\mathrm{OH}$ ) with excitation at $343 \mathrm{~nm}$. To prepare a DMA-solubilized $\mathrm{C}_{12} \mathrm{E}_{6}$ micelle solution, a mixture of $0.75 \mathrm{mM} \mathrm{DMA}$ and $4 \mathrm{mM} \mathrm{C}_{12} \mathrm{E}_{6}$ was stirred overnight. With these concentrations, each micelle solubilizes at least one DM A molecule. Type I fluorescence titrations were carried out by adding a solution of $8 \mathrm{mM}$ CTAC to a mixture of $0.1 \mathrm{~g} / \mathrm{L}$ polymer and $4 \mathrm{mM} \mathrm{C}_{12} \mathrm{E}_{6}$ containing $0.75 \mathrm{mM}$ DMA at constant ionic strengths. Type II titrations were performed using the same procedure as turbidimetry. 


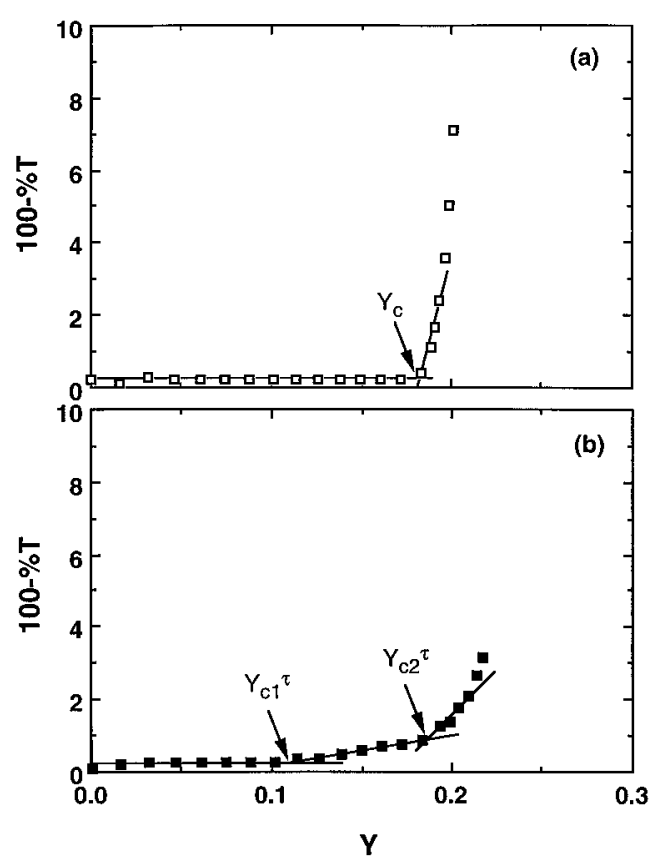

Figure 1. "Type I" turbi di metric titrations (addition of CTAC to a mixture of polymer and $\mathrm{C}_{12} \mathrm{E}_{6}$ at constant ionic strength) in $0.3 \mathrm{M} \mathrm{NaCl}$, for $0.5 \mathrm{~g} / \mathrm{L}$ PAMPS (a) or PyPAMPS (b) +20 $\mathrm{mM} \mathrm{C}_{12} \mathrm{E}_{6}$, using $40 \mathrm{mM}$ CTAC. $Y$ is the mole fraction of CTAC in the mixed micelle.

UV Spectroscopy. UV spectra were recorded on a Spectrophotometer Lambda 19 (Perkin Elmer, Norwalk, CT). Type I titrations were performed using the same procedure as fluorescence titrations.

\section{Results and Discussion}

Type I Turbidimetric Titrations. Solutions containing $0.5 \mathrm{~g} / \mathrm{L}$ PAMPS or PyPAMPS $+20 \mathrm{mM} \mathrm{C}_{12} \mathrm{E}_{6}$ were titrated with $40 \mathrm{mM}$ CTAC at I $=0.3$. In Figure 1 , the turbidity (reported as $100-\% \mathrm{~T}$ ) is plotted against $\mathrm{Y}$, the mole fraction of CTAC in CTAC/ $\mathrm{C}_{12} \mathrm{E}_{6}$ mixed micelles. For PAMPS (Figure la), the turbidity begins to increase at $Y=0.18$, and then abrupt phase separation occurs. These observations agree with those of previous studies on a number of similar polyelectrolytemixed micelle systems; ${ }^{13-15,54,55}$ two critical values of $Y$, one corresponding to the first appearance of turbidity in excess of that of the polymer-free solutions $\left(Y_{c}\right)$, and the other to a more abrupt and dramatic turbidity change $\left(Y_{p}\right)$, corresponding to the phase separation. For PyPAMPS (Figure 1b), turbidity begins to increase gradually at $Y=0.11$ and then increases suddenly at $Y$ $=0.18$, while only the second transition is seen for PAMPS. We designate the first appearance of turbidity as $Y_{\mathrm{Cl}^{\tau}}$, and the point of increasing slope as $Y_{\mathrm{C2}}{ }^{\tau}$ for PyPAMPS. Since $Y_{c 2}{ }^{\tau}$ is equal to $Y_{c}$ of the pyrene-free PAMPS system, it may correspond to the onset of polymer-micelle complex formation at polymeric AMPS sites. On the other hand, $\mathrm{Y}_{\mathrm{Cl}}{ }^{\tau}$ at 0.11 , which is observed only for PyPAMPS, is presumably caused by complex formation between polymeric pyrene sites and micelles. $Y_{p}$ for PAMPS $(Y=0.20)$ is slightly smaller than that for PyPAMPS ( $Y=0.22$ ). According to previous studies, ${ }^{20,21} Y_{c}$ is constant with respect to polymer molecular weight, but $Y_{p}$ varies inversely with $M W$ in a manner consistent with the present results for PAMPS and PyPAMPS (MW's $1 \times 10^{6}$ and $1.1 \times 10^{5}$, respectively). However, the phenomena corresponding to this phase separation, which may include charge neutralization and stoichiometric effects, are not well understood.

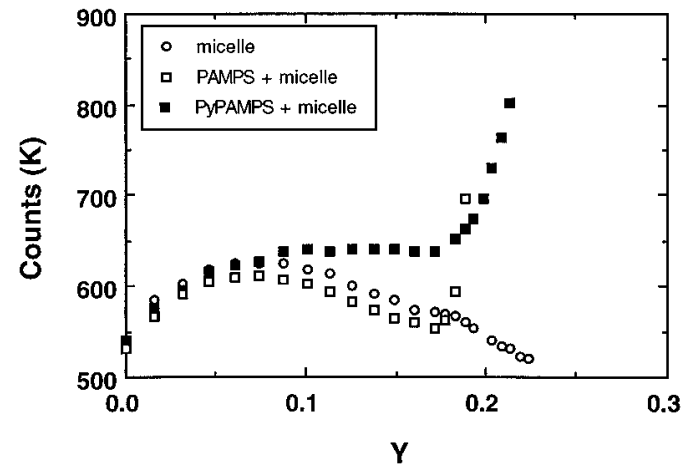

Figure 2. Dependence on $Y$ of total intensity for $0.5 \mathrm{~g} / \mathrm{L}$ PAMPS and PyPAMPS $+20 \mathrm{mM} \mathrm{C}_{12} \mathrm{E}_{6}$, conditions as for Figure 1.

Light Scattering Measurements. QELS and $90^{\circ}$ intensity measurements were carried out on $0.5 \mathrm{~g} / \mathrm{L}$ PAMPS or PyPAMPS $+20 \mathrm{mM} \mathrm{C}_{12} \mathrm{E}_{6}$ titrated with 40 $\mathrm{mM}$ CTAC in $0.3 \mathrm{M} \mathrm{NaCl}$. The photon count rate, measured in thousands per second, is plotted as a function of $Y$ in Figure 2. The data for the polymerfree micelle included for comparison show that the scattering intensity of mixed micelles varies with the mole fraction of ionic surfactant. ${ }^{57,58}$ QELS and size exclusion chromatography showed that this effect is a reflection of the dependence of micelle size on $Y .{ }^{58}$ In the presence of PAMPS, the intensities are identical to those for micelle alone bellow a critical $Y$, and increase abruptly at $Y=0.18$, corresponding to the onset of polymer-micelle interaction. The scattering intensities for PAMPS + micelle bellow $Y_{c}$ are almost equal to those for a polymer-free micelle. Even though $R_{h}$ of PAMPS, $25 \mathrm{~nm}$, is twice as large as that of the micelle, 11-12 $\mathrm{nm}$, we do not observe the scattering from PAMPS because of the large excess of micelles relative to polymer. The intensities for PyPAMPS + micelle coincide with those for micelle al one at $Y<0.10$, but the two diverge at $Y=0.10$, and abruptly separate at $Y=0.18$. Those critical values are in good agreement with the turbidimetric titrations shown in Figure $1 \mathrm{~b}$.

The increase in scattering intensity for PyPAMPS + micelle is relatively modest in the region $Y_{\mathrm{c} 1}<\mathrm{Y}<\mathrm{Y}_{\mathrm{c} 2}$. QELS shows that the apparent mean hydrodynamic radius $\left(R_{h}\right)$ for this system is $13 \mathrm{~nm}$, which may be compared to the values of $11-12 \mathrm{~nm}$ for the micelle and 7.8 for PyPAMPS. However, QELS decay curves are multimodal, presumably due to the presence of excess micelless, and the resolution is inadequate to estimate the size of the complex itself. Nevertheless, the rather low scattering intensity and the apparently small size of the complex suggest an "intrapolymer" (as opposed to multipolymer) complex of relatively low mass. The low mass of the complex is consistent with the proposal that in the region $\mathrm{Y}_{\mathrm{c} 1}<\mathrm{Y}<\mathrm{Y}_{\mathrm{c} 2}$ micelles bind only to the rather small number of pyrene sites on each polymer chain.

Type I Fluorescence Titrations. It is known that the fluorescence of pyrene is quenched by DMA either by forming an exciplex in nonpolar media or by electron transfer from DMA to a singlet-excited pyrene in polar media. 59 In order to investigate the polymer-micelle interaction by fluorescence quenching, we mixed $\mathrm{C}_{12} \mathrm{E}_{6}$ micelles in which the hydrophobic quencher, DMA, was solubilized with PyPAMPS. The quenching of pyrene fluorescence that could occur when DMA-containing micelles associate with pyrene sites on PyPAMPS was 


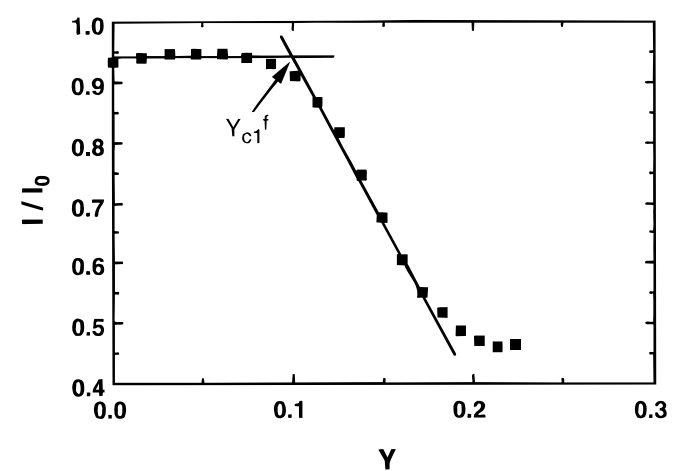

Figure 3. Dependence on $\mathrm{Y}$ of normalized fluorescence intensity in $0.30 \mathrm{M} \mathrm{NaCl}$, for $0.1 \mathrm{~g} / \mathrm{L}$ PyPAMPS $+4 \mathrm{mM} \mathrm{C}_{12} \mathrm{E}_{6}$ containing $0.75 \mathrm{mM}$ DMA, titrated with $8 \mathrm{mM}$ CTAC.

monitored via the intensity change of pyrene fluorescence at $380 \mathrm{~nm}$.

Figure 3 shows the normalized fluorescence intensity, $\mathrm{I} / \mathrm{I}_{0}$, where $\mathrm{I}$ is the fluorescence intensity of $0.1 \mathrm{~g} / \mathrm{L}$ PyPAMPS in the presence of the DMA-containing $\mathrm{C}_{12} \mathrm{E}_{6} /$ CTAC (4 $\mathrm{mM} \mathrm{C}_{12} \mathrm{E}_{6}$ ) at varying $\mathrm{Y}$, and $\mathrm{I}_{0}$ is the fluorescence intensity in the presence of DMA-free micelles at $Y=0$. It is important to note that the fluorescence intensity is independent of $Y$ when DMA is absent; no change in fluorescence intensity is caused by the addition of CTAC (data not shown). A region of stong fluorescence quenching is observed at $0.10<\mathrm{Y}<$ 0.17 , which provides straightforward evidence of the binding between polymeric pyrene sites and DMAcontaining micelles. Fluorescence intensities at lower $Y$ are close to $I_{0}$, but the current precision of the measurements is not adequate to preclude some form of quenching at low $Y$. Nevertheless, the regime of strong quenching can be observed to be initiated at $\mathrm{Y}_{\mathrm{c1}}{ }^{\mathrm{f}}$ $=0.10$, which is in good agreement with the onset of turbidity and scattering intensity change in Figures $1 b$ and 2 , respectively. Therefore, $Y_{\mathrm{cl}}$ corresponds to the minimal surface charge density required to cause micelles to bind to polymeric pyrene sites. Since $Y_{c 1}$ is smaller than $Y_{\mathrm{C}_{2}}$ by $50 \%$, it is suggested that the pyrenelabel enhances the interaction and that micelles bind to pyrene sites preferentially. Furthermore, $\mathrm{I} / \mathrm{I}_{0} \mathrm{de}$ creases with increasing $Y$ at $Y>Y_{c 1}{ }^{f}$, indicating an enhancement of micelle binding as the micelle charge density increases. It is thus revealed that polymeric pyrene provides a hydrophobic site to which mixed micelles bind preferentially.

Type II Turbidimetric and Fluorescence Titrations. Type I titrations using turbidity, $90^{\circ}$ intensity, and fluorescence show that micelles with adequate surface charge density prefer to bind to the pyrene sites. Type II titrations, corresponding to the addition of mixed micelles at constant $Y$ to polymer solution, at constant I, also provide information about the stoichiometry of complex formation. Type II turbidimetric titrations were conducted at $0.1 \mathrm{~g} / \mathrm{L}$ PAMPS or PyPAMPS $+\mathrm{C}_{12} \mathrm{E}_{6} / \mathrm{CTAC}$ mixed micelle in $0.3 \mathrm{M} \mathrm{NaCl}$ at constant $Y$, and the turbidity is plotted as a function of total added surfactant $\left(C_{s}\right)$ in Figure 4. For PAMPS (Figure 4a), the turbidity increases slightly with $C_{s}$ at $\mathrm{Y}=0.18\left(=\mathrm{Y}_{\mathrm{c}}\right)$, while higher turbidity is observed at $\mathrm{Y}$ $=0.20\left(>Y_{c}\right)$, indicating formation of large interpolymer complexes. For PyPAMPS (Figure 4b), the turbidity increases slightly at $\mathrm{Y}=0.16\left(\mathrm{Y}_{\mathrm{c1}}<\mathrm{Y}<\mathrm{Y}_{\mathrm{c} 2}\right)$ even though micelles are binding to the polymeric pyrene sites, while a large increase of turbidity is observed at $Y=0.22$ $\left(>Y_{C_{2}}\right)$. It is noteworthy that turbidity begins to increase

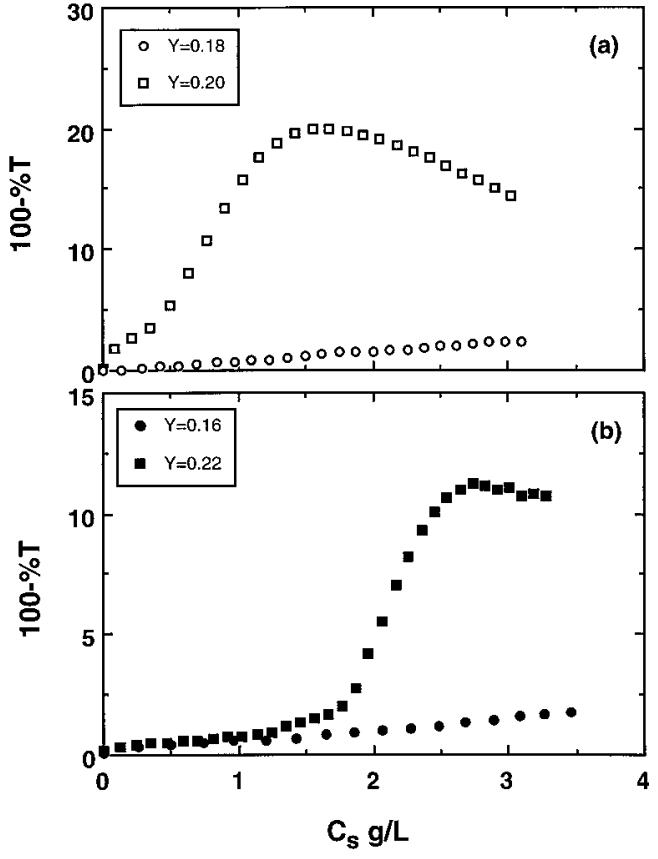

Figure 4. "Type II" turbidimetric titrations (addition of $\mathrm{CTAC} / \mathrm{C}_{12} \mathrm{E}_{6}$ mixed micelle to polymer solution at constant $\mathrm{Y}$ and I) for PAMPS (a) and PyPAMPS (b) in $0.3 \mathrm{M} \mathrm{NaCl}$ at varying $Y$.

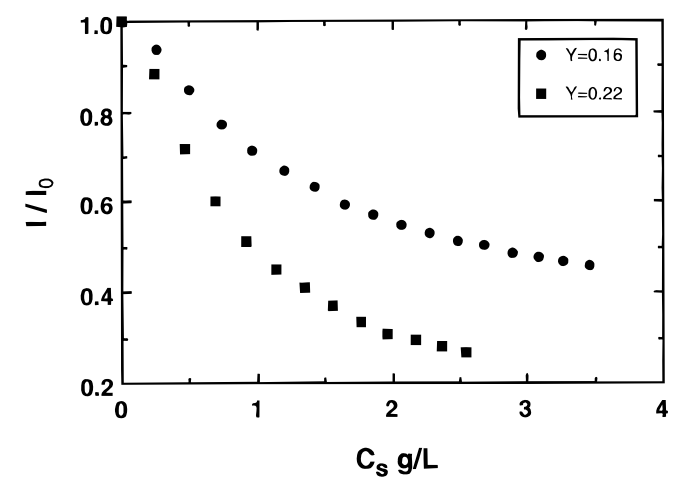

Figure 5. Type II fluorescence titrations for PyPAMPS in 0.3 $\mathrm{M} \mathrm{NaCl}$ at $\mathrm{Y}=0.16$ and 0.22 .

near $C_{s}=0$ with increasing $C_{s}$ for PAMPS, whereas it starts to increase (abruptly) only at $C_{s}=1.6 \mathrm{~g} / \mathrm{L}$ for PyPAMPS. These data are interpreted as follows. For PAMPS, micelles which have adequate surface charge density (at $Y>Y_{c}$ ) to associate with the polyel ectrolyte bind immediately when they are mixed with polymer, leading to large interpolymer complexes observed as high turbidity. For PyPAMPS, micelles initially bind to polymeric pyrene sites even though they have enough surface charge density $\left(Y>Y_{C 2}\right)$ to interact with AMPS sites. Inasmuch as the resultant complex is intrapolymer, turbidity can not increase at low $\mathrm{C}_{\mathrm{s}}$. After completion of binding to pyrene sites, micelles start to associate with AMPS sites consequently forming interpolymer complexes observed as high turbidity.

Figure 5 shows typell titrations of $0.1 \mathrm{~g} / \mathrm{L}$ PyPAMPS with mixed micelles at either $Y=0.16$ or $Y=0.22$ monitored via fluorescence quenching. Upon addition of mixed micelles containing DMA, fluorescence quenching is observed with increasing $C_{5}$. Although only a slight change in turbidity at $Y=0.16$ is seen in Figure $4 \mathrm{~b}$, fluorescence quenching occurs dramatically. These results confirm a formation of the primary intrapolymer complex between polymeric pyrene sites and micelles at $Y_{\mathrm{c} 1}<Y<Y_{\mathrm{c} 2}$, which is hardly seen by turbidity but 


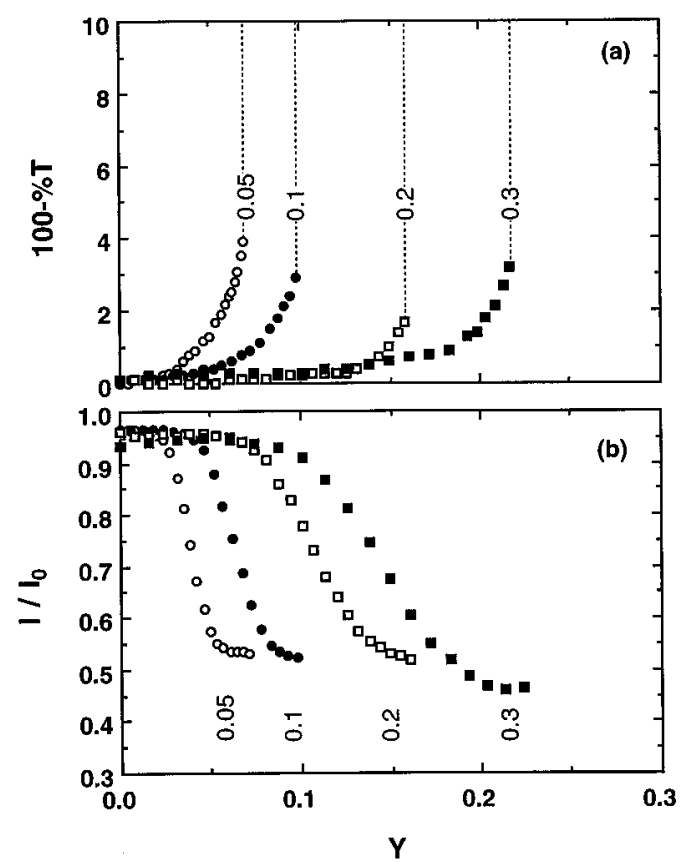

Figure 6. Type I turbidimetric (a) and fluorescence (b) titrations of PyPAMPS at varying ionic strengths.

can be observed by fluorescence. Comparison of the curves for $Y=0.16$ or $Y=0.22$ shows that even though the quencher concentrations are identical and the micelle concentrations are almost equal at any $C_{s}$, higher quenching is observed for micelles with a higher surface charge density. These data imply that the association constant between pyrene sites and micelles depends on the micelle surface charge density and that the electrostatic forces strongly influence the interaction. In other words, the affinity of binding becomes stronger at higher micelle surface charge density; in this case, more micelles bind to polymer and/or micelles have longer residence time.

Type I Turbidimetric and Fluorescence Titrations (E ffect of Ionic Strength). Typel turbidimetric and fluorescence titrations of PyPAMPS $+\mathrm{C}_{12} \mathrm{E}_{6}$ at varying ionic strengths are shown in Figure 6. Critical $Y$ values $\left(Y_{\mathrm{Cl}^{\tau}}{ }^{\tau}, Y_{\mathrm{C2}}{ }^{\tau}\right.$, and $\left.Y_{\mathrm{Cl}}{ }^{\mathrm{f}}\right)$, defined in the same manner as in Figures $1 b$ and 3 , increase with ionic strength. The initial slopes in Figure $6 b$ at $Y<Y_{c 1}{ }^{f}$ vary somewhat erratically. As noted above, the reproducibility of the values in this region of small quenching predudes interpretation of these relatively subtle effects.

Previous studies on a number of polyelectrolytemicelle systems ${ }^{13-15}$, 54-56 reveal ed a linear dependence between $Y_{c}$ and I $I^{1 / 2}$. As shown in Figure 7, both $Y_{c 1}$ and $Y_{C 2}$ depend linearly on $I^{1 / 2}$ in the present system. Although turbidity, fluorescence, and QELS all reveal a hydrophobic effect on the interaction between polymeric pyrene sites and micelles, the linear dependence of $Y_{c 1}$ on $I^{1 / 2}$ suggests that the interaction is also controlled by electrostatic forces.

Earlier studies 53,60 have led to an empirical relationship that describes the critical conditions for complexation

$$
\sigma_{\mathrm{c}} \xi \kappa^{-1}=\text { constant }
$$

where $\sigma_{\mathrm{c}}$ is the critical micelle surface charge density which is proportional to $Y_{c}, \xi$ is the linear charge density of polymer, and $\kappa^{-1}$, the Debye length, varies with $\mathrm{I}^{-1 / 2}$.

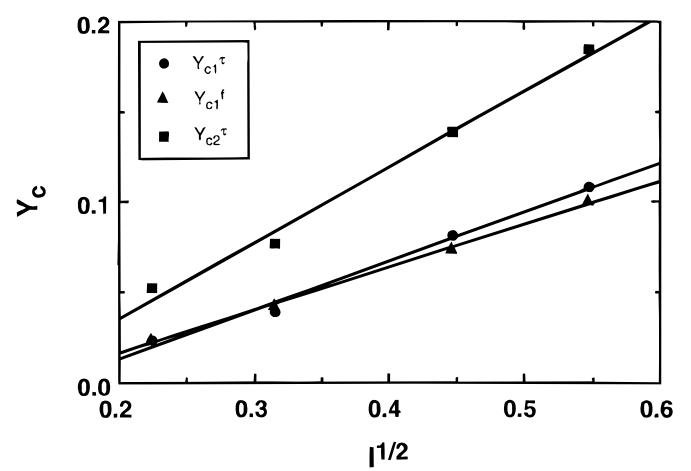

Figure 7. I onic strength dependence of $Y_{\mathrm{Cl}}{ }^{\tau}, Y_{\mathrm{Cl}}{ }^{\mathrm{f}}$, and $\mathrm{Y}_{\mathrm{C2}}{ }^{\tau}$ for PyPAMPS/ $\mathrm{C}_{12} \mathrm{E}_{6} / \mathrm{CTAC}$ (from data of Figure 6).

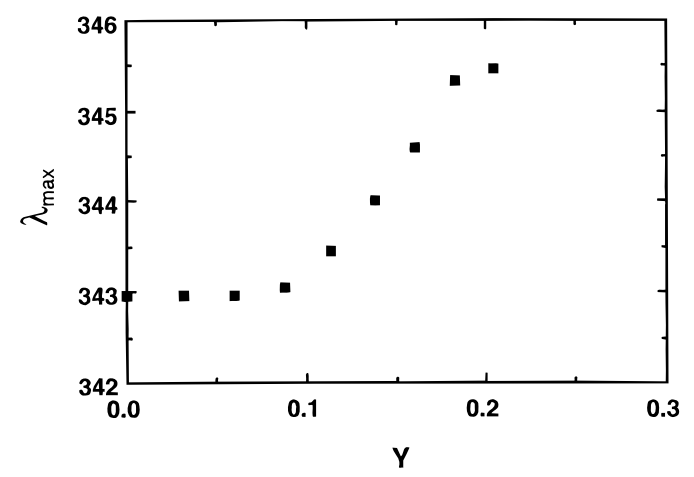

Figure 8. Dependence of $\lambda_{\max }$ on $Y$ for $0.1 \mathrm{~g} / \mathrm{L}$ PyPAMPS +4 $\mathrm{mM} \mathrm{C}_{12} \mathrm{E}_{6}$ titrated with $8 \mathrm{mM} \mathrm{CTAC}$ in $0.3 \mathrm{M} \mathrm{NaCl}$.

This relationship has been theoretical ly rationalized by Odijk. ${ }^{26}$ From the above relationship, we can infer that

$$
\mathrm{d} \sigma_{\mathrm{d}} \mathrm{d} \kappa \propto \xi^{-1}
$$

The binding affinity of polymers for micelles is stronger at larger $\xi$; in this case, the slope $\left(\mathrm{d} \sigma_{d} / \mathrm{d} \kappa\right)$ becomes smaller. Therefore, the smaller slope means a higher binding affinity of polymer for micelles. We observe a smaller slope for $Y_{c 1}$ than for $Y_{c 2}$ in Figure 7. Since $Y_{c 1}$ corresponds to the binding between polymeric pyrene sites and micelles, the pyrene sites of PAMPS strengthen the affinity of binding. In other words, because $Y_{c}$ is proportional to the minimal micelle surface charge density to bind to polymers, and $Y_{\mathrm{c} 1}$ is smaller than $Y_{c_{2}}$ by $50 \%$ at constant I, micelles need $50 \%$ more charge to bind to AMPS sites than to pyrene sites. We thus conclude that there is a conjoint effect of hydrophobic and electrostatic forces on the interaction between the pyrene-labeled PAMPS and the $\mathrm{C}_{12} \mathrm{E}_{6} / \mathrm{CTAC}$ mixed micelles.

UV Spectra. Because the UV spectra of aromatic compounds are sensitive to the polarity of the medium, they are useful as probes of microenvironment polarity. ${ }^{61-63}$ Mukerjee and Cardinal ${ }^{61}$ discussed the microenvironment polarity and spatial distribution of such probes in micelles. Kido et al. ${ }^{40}$ used pyridinium dicyanomethylide labeled polymers as solvatochromic probes and found a $\lambda_{\max }$ shift at the CAC of poly(Nsubstituted acrylamide)s and SDS.

Type I titrations were carried out at $0.1 \mathrm{~g} / \mathrm{L}$ PyPAMPS $+4 \mathrm{mM} \mathrm{C}_{12} \mathrm{E}_{6}$ with $8 \mathrm{mM} \mathrm{CTAC}$ in $0.3 \mathrm{M} \mathrm{NaCl}$. $\lambda_{\max }$ values of pyrene are plotted as a function of $Y$ in Figure 8. While UV spectra were identical at $0<Y<0.10$, we observe a red shift starting from a critical $Y(=0.10)$. The initial point of the $\lambda_{\max }$ shift corresponds to the onset of complex formation between polymeric pyrene 
Table 1. $\lambda_{\max }$ of PyPAm in Various Solvents

\begin{tabular}{lcc}
\hline \multicolumn{1}{c}{ solvent } & dielectric constant & $\lambda_{\text {max }} / \mathrm{nm}$ \\
\hline water & 78.5 & 341.74 \\
acetonitrile & 37.5 & 341.88 \\
ethanol & 24.3 & 342.00 \\
ethylene oxide & 13.0 & $345.16^{\mathrm{a}}$ \\
toluene & 2.38 & 345.37 \\
a In poly(ethylene glycol), $\mathrm{MW}=200$. &
\end{tabular}

and micelles, in that $Y_{c}$ determined from the $\lambda_{\max }$ shift is in a good agreement with $Y_{\mathrm{cl}}{ }^{\tau}$ and $Y_{\mathrm{cl}}{ }^{\mathrm{f}}$.

Table 1 shows $\lambda_{\max }$ values of a pyrene probe, PyPAm, which has a structure similar to that of polymeric pyrene, in various solvents. $\lambda_{\max }$ varies inversely with solvent polarity. Since $\lambda_{\max }$ of polymeric pyrene is observed to increase at $Y>Y_{c}$, this suggests that pyrene sites are in a more nonpolar environment at high $Y$, i.e., due to penetration into micelles. At $Y=0.20\left(>Y_{\mathrm{c} 2}\right)$, the $\lambda_{\max }$ value reaches $345.4 \mathrm{~nm}$, close to the value of this probe in ethylene oxide or toluene. Since the palisade layer of the micelle has a dielectric constant of $\epsilon=40-50,61$ much larger than pure EO, the high $\lambda_{\max }$ value at $Y=0.20 \mathrm{implies}$ that polymeric pyrene resides at or near the micelle hydrophobic core.

The previous discussion reveals that pyrene-labeled PAMPS interacts with oppositely charged mixed micelles through conjoint hydrophobic and electrostatic forces. Although micelles associate preferentially with pyrene binding sites by hydrophobic interaction, the binding between these sites and micelles is strongly dominated by the electrostatic forces. This proposal explains (1) the observation of two different $Y_{C}{ }^{\prime} S\left(Y_{c 1}{ }^{\tau}\right.$ and $Y_{\mathrm{C2}^{\tau}}$ ) in turbidity and QELS titrations (Figures $1 \mathrm{~b}$ and 2), (2) the good agreement of $Y_{c 1}{ }^{\tau}$ with $Y_{c 1}{ }^{f}$ (Figures $1 \mathrm{~b}$ and 3), and (3) the linear relationship between $Y_{c}$ and $I^{1 / 2}$ (Figure 7). However, it does not explain why fluorescence quenching and $\lambda_{\max }$ shifts occur gradually for $Y_{\mathrm{C} 1}<\mathrm{Y}<\mathrm{Y}_{\mathrm{C2}}$ (Figures 3 and 8, respectively). Four possible reasons may account for these observations: (1) If mixed micelles have a compositional distribution, $Y$ is only an average value. If micelles must have adequate surface charge density to interact with polymers, the number of such "active micelles" increases with increasing $\mathrm{Y}$. Then, both $\mathrm{I} / \mathrm{I}_{0}$ and $\lambda_{\max }$ can change gradually al ong with the number of micelles binding to polymeric pyrene. Such a distribution of micelle compositions was predicted in early studies ${ }^{15}$ and recently demonstrated by capillary electrophoresis. ${ }^{64}$ (2) If complexation is a dynamic process and the residence time of micelles on polymers depends on micelle surface charge density, $\mathrm{I} / \mathrm{I}_{0}$ and $\lambda_{\max }$ can also change continuously. In this case, these values reflect the balance of the encounter rate constant and residence time. The dynamics of complex formation has been examined using timeresolved fluorescence decay measurement. ${ }^{46}$ (3) If the complex is in equilibrium with free micelles and polymers, the corresponding "binding constant" may vary with micelle surface charge density. In this case, $I / I_{0}$ and $\lambda_{\max }$ reflect the change of the binding constant with $Y$. (4) Strong binding of the micelles due to electrostatic forces may cause pyrene to penetrate more deeply at higher $\mathrm{Y}$. Not only $\lambda_{\max }$, but al so the quenching rate between pyrene and DMA inside the micelle may be affected by the location of pyrene. In this case, $\mathrm{I} / \mathrm{I}_{0}$ and $\lambda_{\max }$ can vary gradually with increasing $\mathrm{Y}$.

In type II fluorescence titrations (Figure 5), higher quenching was observed at $Y=0.22$ than at $Y=0.16$, even though quencher and micelle concentrations are equal. This indicates the dependence of the quenching constant on micelle surface charge density. This effect can be explained by hypotheses similar to the ones given above; namely that an increase in $Y$ leads to an increase in (1) the number of "active" micelles, (2) the residence time of micelles on polymer, (3) the micelle-polymer association constant, or (4) the depth of penetration of pyrene inside micelles, increasing the first-order quenching rate. All these effects can explain an enhancement of quenching with increase in $Y$.

Acknowledgment. This work was supported by Grant DMR9619722 from the Division of Materials Research, National Science Foundation, and by a Grantin Aid of Research from Shiseido Co.

\section{References and Notes}

(1) Li, Y.; Dubin, P. L. In Structure and Flow in Surfactant Solutions, Herb, C. A., Prud'homme, R. K., Eds., ACS Symposium Series 578; American Chemical Society: Washington, DC, 1994; Chapter 23, p 320.

(2) Goddard, E. D. J . Am. Oil . Chem. Soc. 1994, 71, 1.

(3) Wei, Y. C.; Hudson, S. M. J . Macromol. Sci.-Rev. Macromol. Chem. Phys. 1995, 35, 15.

(4) Brackman, J . C.; Engberts, J . B. F. N. Chem. Soc. Rev. 1993, $22,85$.

(5) Goddard, E. D. Colloids Surf. 1986, 19, 301.

(6) Hayakawa, K.; Kwak, J. C. T. In Cationic Surfactants. Physical Chemistry; Rubingh, D. N., Holland, P. M., Eds; Marcel Dekker: New York, 1991; Chapter 5, p 189.

(7) Lindman, B.; Khan, A.; Marques, E.; Miquel, M.; Piculell, L.; Thalberg, K. Pure Appl. Chem. 1993, 22, 85.

(8) Nagarajan, R. Colloids Surf. 1985, 13, 1.

(9) Nagarajan, R. J . Chem. Phys. 1989, 90, 1980.

(10) Ruckenstein, E; Huber, G.; Hoffmann, H. Langmuir 1987, 3, 382.

(11) François, J . C.; Dayantis, J .; Sabbadin, J . Eur. Polym. J . 1985, $43,491$.

(12) Dubin, P. L.; Gruber, J . H.; Xia, J .; Zhang, H. J . Colloid Interface Sci. 1992, 148, 35.

(13) Dubin, P. L.; Rigsbee, D. R.; McQuigg, D. W. J . Colloid Interface Sci. 1985, 105, 509.

(14) McQuigg, D. W.; Kaplan, J . I.; Dubin, P. L. J . Phys. Chem. 1992, 96, 1973.

(15) Dubin, P. L.; Oteri, R. J . Colloid Interface Sci. 1983, 95, 453.

(16) Dubin, P. L.; Davis, D. D. Macromolecules 1984, 17, 1294.

(17) Dubin, P. L.; Rigsbee, D. R.; Gan, L. M.; Fallon, M. A. Macromolecules 1988, 21, 2555.

(18) Xia, J .; Dubin, P. L.; Kim, Y. J . Phys. Chem. 1992, 96, 6805.

(19) Li, Y.; Dubin, P. L.; Dautzenberg, H.; Lück, U.; Hartmann, J .; Tuzar, Z. Macromolecules 1995, 28, 6795.

(20) Li, Y.; Xia, J .; Dubin, P. L. Macromolecules 1994, 27, 7049.

(21) Li, Y.; Dubin, P. L.; Havel, H. A.; Edwards, S. L.; Dautzenberg, H. Macromolecules 1995, 28, 3098.

(22) Xia, J .; Zhang, H.; Rigsbee, D. R.; Dubin, P. L.; Shaikh, T. Macromol ecules 1993, 26, 2759.

(23) Evers, O. A.; Fleer, G. J .; Scheutjens, J . M. H. M.; Lyklema, . . . Colloid Interface Sci. 1986, 111, 446.

(24) Muthukumar, M. J . Chem. Phys. 1987, 86, 7230.

(25) Wallin, T.; Linse, P. Langmuir 1996, 12, 305.

(26) Odijk, T. Langmuir 1991, 7, 1991.

(27) Cabane, B.; Duplessix, R. J . Phys. (Paris) 1982, 43, 1529.

(28) Ware, B. R.; Haas, D. D. In Fast Methods in Physical Biochemistry and Cell Biology; Sha'afi, R. I., Fernadez, S. M., Eds.; Elsevier: Amsterdam, 1983.

(29) Xia, J .; Dubin, P. L.; Izumi, T.; Hirata M.; Kokufuta, E. J Polym. Sci., Part B: Polym. Phys. 1996, 34, 497.

(30) Cabane, B. J . Phys. Chem. 1977, 81, 1639.

(31) Fishman, M. L.; Eirich, F. R. J . Phys. Chem. 1971, 75, 3135.

(32) Shirahama, K. Colloid Polym. Sci. 1974, 252, 978,

(33) J ones, M. N. J Colloid Interface Sci. 1967, 23, 36.

(34) Schwuger, M. J . J Colloid Interface Sci. 1973, 43, 491.

(35) Buckingham, J. H.; Lucassen, J.; Hollway, F. J . Colloid Interface Sci. 1978, 67, 423.

(36) Murata, M.; Arai, H. J Colloid Interface Sci. 1973, 44, 475.

(37) Rigsbee, D. R.; Dubin, P. L. Langmuir 1996, 12, 1928.

(38) Sudbeck, E. A.; Dubin, P. L.; Curran, M. E.; Skelton, J . J . Colloid Interface Sci. 1991, 142, 512.

(39) Tokiwa, F.; Tujii, K. Bull. Chem. Soc. J pn. 1973, 46, 2684. 
(40) Kido, J .; Imamura, Y.; Muramoto, N.; Nagai, K. J . Colloid Interface Sci. 1992, 150, 338.

(41) Dubin, P. L.; Thé, S. S.; Gan, L. M.; Chew, C. H. Macromolecules 1990, 23, 2500.

(42) Abuin, E. B.; Scaiano, J . C. J . Am. Chem. Soc. 1984, 106, 6274.

(43) Almgren, M.; Hansson, P.; Mukhtar, E.; van Stam, J . Langmuir 1992, 8, 2405.

(44) Winnik, F. M.; Winnik, M. A.; Tazuke, S. J . Phys. Chem. 1987, 91, 594.

(45) Hu, Y.; Zhao, C.; Winnik, M. A. Langmuir 1990, 6, 880.

(46) Mizusaki, M.; Morishima, Y.; Yoshida, K.; Dubin, P. L. to be submitted.

(47) Winnik, F. M.; Ringsdorf, H.; Venzmer, J . Langmuir 1991, 7, 905.

(48) Winnik, F. M.; Ringsdorf, H.; Venzmer, J . Langmuir 1991, 7, 912.

(49) Winnik, F. M.; Regismond, S. T. A.; Goddard, E. D. Coll. Surf. 1996, 243.

(50) Goddard, E. D.; Leung, P. S. Langmuir 1992, 8, 1499.

(51) Morishima, Y.; Tominaga, Y.; Kamachi, M.; Okada, T.; Hirata, Y.; Mataga, N. J . Phys. Chem. 1991, 95, 6027.

(52) Morishima, Y.; Seki, M.; Tominaga, Y.; Kamachi, M. J . Polym. Sci., Polym. Chem. Ed. 1992, 30, 2099.
(53) Dubin, P. L.; Chew, C. H.; Gan, L. M. J . Colloid Interface Sci. 1989, 128, 566.

(54) Dubin, P. L.; Vea, M. E. Y.; Fallon, M. A.; Thé, S. S.; Rigsbee, D. R.; Gan, L. M. Langmuir 1990, 6, 1422.

(55) Dubin, P. L.; Davis, D. Colloids Surf. 1985, 13, 113.

(56) Dubin, P. L.; Thé, S. S.; McQuigg, D. W.; Chew, C. H.; Gan, L. M. Langmuir 1989, 5, 89.

(57) Nishikido, N. J . Colloid Interface Sci. 1987, 120, 495.

(58) Dubin, P. L.; Principi, J . M.; Smith, B. A.; Fallon, M. A. J . Colloid Interface Sci. 1989, 127, 558.

(59) Lakowicz, J. R. In Principles of Fluorescence Spectroscopy; Plenum Press, New York and London, 1983; Chapter 9.

(60) Davis, R. M.; Zhang, H.; Dubin, P. L.; McQuigg D. W. Polym. Prepr. 1991, 32, 292.

(61) Mukerjee, P.; Cardinal, J . R. J . Phys. Chem. 1978, 82, 1620.

(62) Rehfeld, S. J . J . Phys. Chem. 1970, 74, 117.

(63) Rehfeld, S. J.J . Phys. Chem. 1971, 75, 3905.

(64) Zhang, H.; Dubin, P. L. J . Colloid Interface Sci. 1997, 186, 264.

MA970576H 